\title{
TRENDS OF STROKE SUBTYPES MORTALITY IN SAO PAULO, BRAZIL (1996-2003)
}

\author{
Paulo A. Lotufo ${ }^{1,2}$, Isabela M. Benseñor ${ }^{1}$
}

\begin{abstract}
The decline of stroke mortality rates has been described in Brazil; however, there is no data about stroke subtypes. We described the changes of stroke mortality rates in the city of Sao Paulo (19962003) emphasizing intracerebral hemorrhage and cerebral infarction. We categorized mortality data by gender and 10-year age-strata from 30 to 79 years-old. For men, an annual reduction of all types of stroke $(-3.9 \%)$, and of stroke subtypes as intracerebral hemorrhage $(-3.0 \%)$ and cerebral infarction was observed $(-2.7 \%)$ as well as, a decline of ill-defined stroke $(-7.4 \%)$. For women, a decline was observed for all types of stroke $(-3.3 \%)$ and for ill-defined stroke $(-12 \%)$. However, the switch of ill-defined cases to stroke subtype categories due to a better clinical diagnosis blurred a real decline of both cerebral infarction and intracerebral hemorrhagic stroke among women.
\end{abstract}

KEY WORDS: cerebrovascular disorders, mortality, cerebral infarction, intracerebral hemorrhage, epidemiology.

\section{Tendência da mortalidade pelos subtipos da doença cerebrovascular (1996-2003)}

RESUMO - O declínio da mortalidade pela doença cere b rovascular no Brasil é conhecido, porém há poucos dados sobre a evolução temporal dos dois principais subtipos, a hemorragia parenquimatosa e o infarto ce rebral. As modificações temporais dos subtipos de doença cerebrovascular foram estudadas na cidade de São Paulo entre 1996 e 2003 por gênero e faixa etária decenal entre os 30 e 79 anos. Para os homens detectou-se redução anual para todo os tipos $(-3,9 \%)$, para hemorragia parenquimatosa $(-3,0 \%)$, para infart o ce rebral $(-2,7 \%)$ bem como para os casos mal definidos (-7.4\%). Para as mulheres somente houve variação significativa para todos os tipos da doença cere b rovascular $(-3,3 \%)$ e para os casos mal definidos $(-12 \%)$. Concluindo, as taxas de doença cerebrovascular estão em queda, porém entre as mulheres devido à melhoria do diagnóstico clínico houve migração de casos mal definidos para casos bem definidos. Devido a isso não foi possível detectar declínio nas taxas de mortalidade pelos subtipos de doença cerebrovascular.

PALAVRAS-CHAVE: doença cerebrovascular, mortalidade, infarto cerebral, hemorragia cerebral, epidemiologia.

Stroke mortality rates are declining in Brazil since the $1970{ }^{\prime 1-5}$. Until now, there is no specific study addressing the tendency of mortality rates considering the different stroke subtypes in Brazil. It is a thoughtp rovoking question to answer because the clinical and radiographic distinction between the two broadest stroke subcategories - cerebral infarction and cerebral hemorrhage - is not easy, and the access to radiographic exams has not been the same during time. As a consequence of this, considerable proportion of deaths has been classified as "ill-defined stroke". The improvement of the diagnosis with more access to radiographic exams can reduce the number of ill defined cases. This effect causes an artificial upward mortality trend from either ischemic or hemorrhagic subtypes. Other concern about the artificial trends is derived from the change of stroke classification of the International Classification of Diseases as occurred in Brazil, when the Tenth Revision was introduced (1996) ${ }^{6}$.

It is very important to describe the tendencies of most frequent categories of stroke because they could have different behaviors across countries. In England and Wales during the $20^{\text {th }}$ century, for example, the behavior of cerebral infarction was mo re similar to the pattern observed for coro $n$ a ry heart disease mortality trends than for intracerebral he mo rrhage. As a corollary, the ratio between cerebral infarction and intracerebral hemorrhage could be an index to be compared during time to verify the epidemiologic transition from a hypertensivelinked stroke (intracerebral hemorrhage) to an atherosclerotic-associated stroke (cerebral infarction) ${ }^{7}$.

Our aim is to analyze the trends of stroke mor-

${ }^{1}$ M.D, Dr PH, Department of Internal Medicine, School of Medicine, University of Sao Paulo, São Paulo SP, Brazil (USP); ${ }^{2}$ M.D, Division of Internal Medicine, Hospital Universitário, USP. Dr. Lotufo and Dra. Bensenor are recipients of award grant from Conselho Nacional de Pesquisa, Brasília, Brazil.

Received 28 February 2005, received in final form 1 August 2005. Accepted 22 August 2005.

Dr. Paulo A. Lotufo - Hospital Universitário USP - Av. Lineu Prestes 2565 - 05508-900 São Paulo SP - Brasil. E-mail: palotufo@hu.usp. br 
tality rates according to stroke subtypes in the city of Sao Paulo. As published previously, the city of São Paulo (Brazil) has a complete and complex system of mortality surveillance that allow us to verify the stroke subtypes' pro p o rtion by age-strata and gender ${ }^{6}$.

\section{METHOD}

We used the Tenth International Classification of Diseases (chapter I) considering only the following stroke subtypes: ill-defined stroke (ICD-10:I64); intracerebral hemorrhage (ICD-10:I61); cerebral infarction (ICD-10:I63); late-effects of cerebrovascular diseases (ICD-10:I69) and subarachnoideal hemorrhage (ICD-10:160).

Mortality data was obtained from the city of São Paulo health statistic system (PRO-AIM, "Programa de Aprimoramento das Informações de Mortalidade") and they were categorized by gender and 10-year age-strata ( $f$ rom 30-39 years-old to 70-79 years-old). We analyzed all deaths from 1996 to 2003.

Mortality rates were calculated using the population d e t e rmined from the Brazilian National Census in 2000 with inference of the past and future years from the year 2000 calculated by the Instituto Brasileiro de Geografia e Estatística. Adjustment for age was calculated by direct method using as standard the whole population of the city of Sao Paulo in the year 2000. The weights applied for age-adjustment were for each age-strata 0.37(30-39 years-old); 0.29 ( $40-49$ years-old); $0.18(50-59$ years-old); 0.11 (60-69 years-old and 0.06 ( $70-79$ years-old).

To verify the tendency during this time interval, we applied a linear regression analysis using a SPSS 10 (Statistical Package for Social Sciences version 10, Chicago, USA) that yielded an equation that can see described as "mortality ratei $=a+b x$ yeari , where $i$ is" the year of observation. The annual decline was derived from the re gression equation dividing the regression coefficient (b) by the constant (a).

\section{RESULTS}

There was a substantial reduction of deaths classified as "ill-defined stroke" from 1996 to 2003. In 1996, 2,216 men, and 1,769 women deceased from st roke (only for the subtypes in analyses) in the city of São Paulo with a proportion of $40.8 \%$ and $40.7 \%$ of "ill-defined stroke" for both men and w omen, respectively. By contrast, in 2003, the number of deaths was lower for men $(1,831)$ and women $(1,657)$ and the pro portion of "ill-defined stroke" was also lower for men (26.3\%) and women $(25.5 \%)$. Table 1 shows the proportion of stroke deaths in comparison to all cardiovascular deaths. There was a significant decrease of ill-defined cases for men (relative decrease of $44 \%$ ) and women (relative decrease of $39 \%$ ) with a stable proportion of stroke subtypes during this time interval.

Figure displays the age-adjusted mortality rates from 1996 to 2003 for men and women with the linear regression curve. In Table 2, the annual diffe rence is showed for all cardiovascular diseases, all types of stroke and for each stroke subtype. For men, there was a significant decline for all situations, except for subarachnoideal hemorrhage and the "late-effects" of cerebrovascular disease whose rates did not alter materially. For women, despite of a substantial decline of all cardiovascular dise-

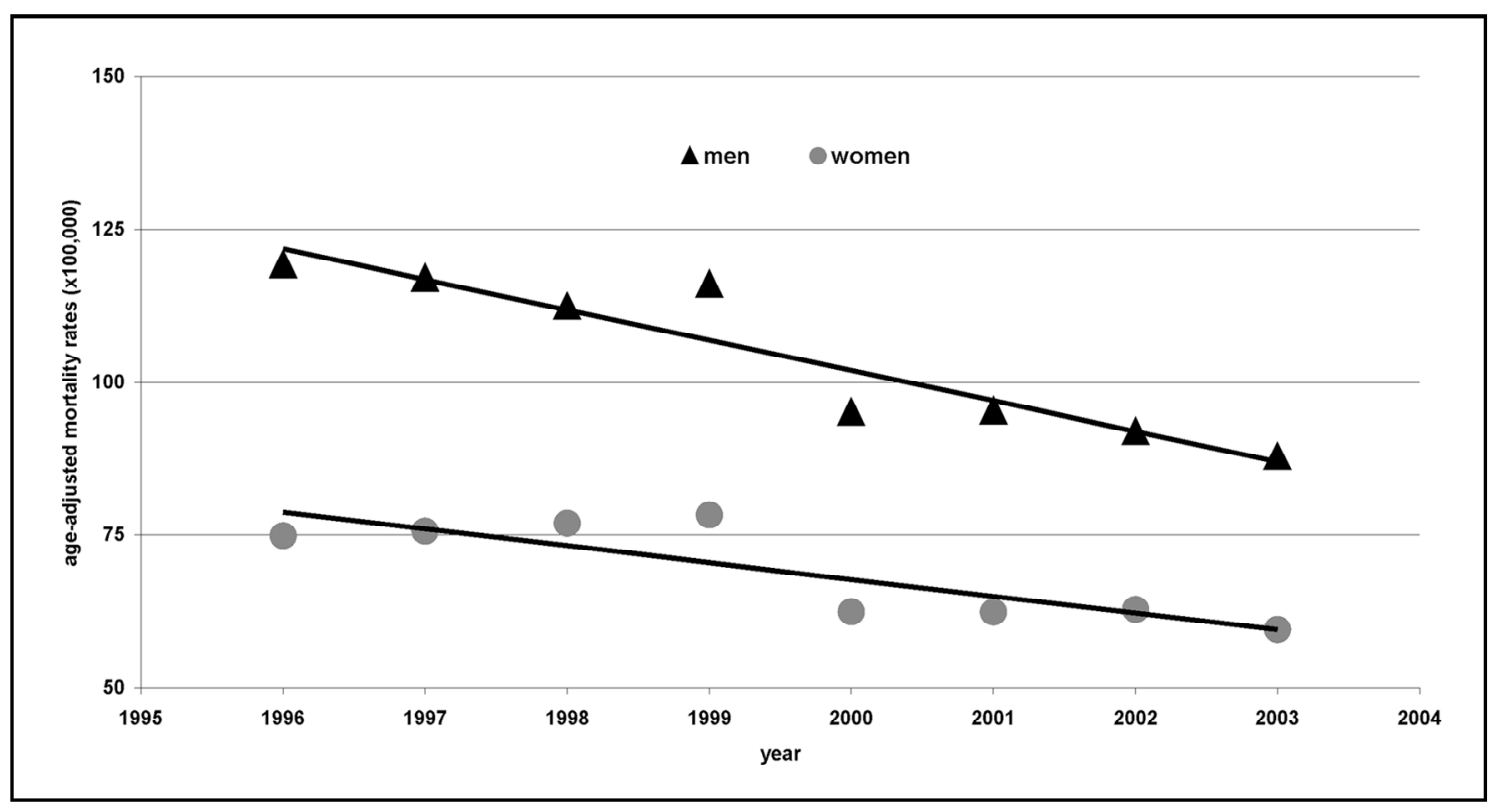

Figure. Age adjusted stroke mortality rates in the city of Sao Paulo, 1996-2003. 
Table 1. Proportion of deaths (in percentage) of stroke subtypes in relation to all cardiovascular diseases from 1996 to 2003 in Sao Paulo City.

\begin{tabular}{lcccccccc}
\hline & 1996 & 1997 & 1998 & 1999 & 2000 & 2001 & 2002 & 2003 \\
\hline & & \multicolumn{7}{c}{ Men } \\
ill-defined stroke (I64)) & 10.4 & 10.0 & 8.9 & 8.8 & 7.8 & 7.1 & 6.5 & 5.8 \\
Intracerebral hemorrhage (I61) & 6.4 & 6.6 & 7.0 & 7.2 & 6.2 & 6.3 & 6.7 & 6.4 \\
Cerebral infarction (I63) & 5.0 & 4.5 & 4.2 & 4.3 & 5.0 & 5.0 & 4.7 & 4.7 \\
Late-effects of cerebrovascular diseases (I69) & 2.3 & 2.7 & 2.8 & 2.7 & 2.8 & 3.3 & 3.5 & 3.4 \\
subarachnoideal hemorrhage (I60) & 1.3 & 1.2 & 1.5 & 1.7 & 1.8 & 1.9 & 1.9 & 1.9 \\
Total & 25.4 & 25.1 & 24.4 & 24.7 & 23.6 & 23.6 & 23.3 & 22.2 \\
& & & & & & & & \\
& & & & & & & & \\
ill-defined stroken (I64) & 11.3 & 11.1 & 10.4 & 10.0 & 8.2 & 8.0 & 7.3 & 6.9 \\
Intracerebral hemorrhage (I61) & 6.4 & 6.2 & 7.0 & 7.8 & 6.9 & 7.2 & 7.0 & 6.4 \\
Cerebral infarction (I63) & 4.6 & 4.5 & 3.9 & 4.7 & 5.2 & 5.2 & 5.5 & 5.3 \\
Subarachnoideal hemorrhage (I60) & 3.0 & 3.7 & 4.0 & 3.7 & 4.0 & 4.0 & 4.5 & 5.5 \\
Late-effects of cerebrovascular diseases (I69) & 2.4 & 2.3 & 2.4 & 2.5 & 2.8 & 2.9 & 3.3 & 2.9 \\
Total & 27.6 & 27.8 & 27.8 & 28.6 & 27.0 & 27.3 & 27.5 & 27.0 \\
\hline
\end{tabular}

Table 2. Annual difference (in percentage) using linear regression of age-adjusted mortality rates from 1996 to 2003 in the city of Sao Paulo.

\begin{tabular}{|c|c|c|}
\hline & Annual difference & $\mathrm{p}$ \\
\hline \multicolumn{3}{|c|}{ Men } \\
\hline all cardiovascular & -2.9 & $<0.001$ \\
\hline all stroke & -3.9 & $<0.001$ \\
\hline ill-defined stroke & -7.4 & $<0.001$ \\
\hline intracerebral hemorrhage & -3.0 & $<0.05$ \\
\hline cerebral infarction & -2.7 & $<0.01$ \\
\hline subarachnoideal hemorrhage & 4.6 & 0.11 \\
\hline late-effects of cerebrovascular disease & 1.6 & 0.22 \\
\hline \multicolumn{3}{|c|}{ Women } \\
\hline all cardiovascular & -3.2 & $<0.01$ \\
\hline all stroke & -3.3 & $<0.01$ \\
\hline ill-defined stroke & -12.0 & $<0.001$ \\
\hline intracerebral hemorrhage & -2.6 & 0.19 \\
\hline cerebral infarction & -0.5 & 0.58 \\
\hline subarachnoideal hemorrhage & 3.4 & 0.11 \\
\hline late-effects of cerebrovascular disease & 3.3 & 0.73 \\
\hline
\end{tabular}

Table 3. Annual difference in percentage (and $p$ value) of mortality rates according to age-strata from 1996 to 2003 in the city of Sao Paulo.

\begin{tabular}{|c|c|c|c|}
\hline & $\begin{array}{c}\text { all } \\
\text { strokes }\end{array}$ & $\begin{array}{l}\text { intracerebral } \\
\text { hemorrhage }\end{array}$ & $\begin{array}{c}\text { cerebral } \\
\text { infarction }\end{array}$ \\
\hline \multicolumn{4}{|c|}{ Men } \\
\hline 30-39 years-old & $-0.5(<0.01)$ & $-5.6(<0.05)$ & $0,5(0,21)$ \\
\hline 40-49 years-old & $-4.4(<0.01)$ & $-2.4(0.15)$ & $-4,5(<0.05)$ \\
\hline $50-59$ years-old & $-3.1(<0.05)$ & $-3.8(0.06)$ & $0,0(0.99)$ \\
\hline $60-69$ years-old & $-4.7(<0.001)$ & $-4.0(<0.01)$ & $-4,1(0.19)$ \\
\hline 70-79 years-old & $-3.5(<0.05)$ & $-0.5(0.79)$ & $-1,8(<0.05)$ \\
\hline \multicolumn{4}{|c|}{ Women } \\
\hline $30-39$ years-old & $-3.0(0.09)$ & $-4.7(<0.05)$ & $0,9(0.19)$ \\
\hline $40-49$ years-old & $-2.4(0.11)$ & $-4.4(0.12)$ & $0,2(0.55)$ \\
\hline $50-59$ years-old & $-2.9(<0.01)$ & $-1.4(0.33)$ & $0,0(0.98)$ \\
\hline $60-69$ years-old & $-3.6(<0.01)$ & $-2.1(0.33)$ & $1,5(0.26)$ \\
\hline 70-79 years-old & $-3.9(<0.05)$ & $-0.60(0.72)$ & $-0,9(0.48)$ \\
\hline
\end{tabular}


Table 4. Temporal changes of the ratio between deaths from cerebral infarction and from intracerebral hemorrhage in the city of Sao Paulo.

\begin{tabular}{lllllll}
\hline & $30-39 *$ & $40-49$ & $50-59$ & $60-69$ & $70-79$ & $30-79$ \\
\hline 1996 & & & & & \\
1997 & 0.25 & 0.35 & 0.45 & 1.01 & 1.95 & 0.78 \\
1998 & 0.20 & 0.30 & 0.46 & 0.93 & 1.44 & 0.68 \\
1999 & 0.33 & 0.22 & 0.44 & 0.82 & 1.21 & 0.60 \\
2000 & 0.26 & 0.20 & 0.30 & 0.84 & 1.37 & 0.59 \\
2001 & 0.34 & 0.33 & 0.48 & 0.96 & 1.68 & 0.80 \\
2002 & 0.09 & 0.35 & 0.58 & 0.95 & 1.59 & 0.79 \\
2003 & 0.23 & 0.25 & 0.54 & 0.81 & 1.48 & 0.71 \\
& 0.36 & 0.28 & 0.47 & 1.04 & 1.37 & 0.74 \\
1996 & & & & & 1.59 & 0.72 \\
1997 & 0.17 & 0.18 & 0.43 & 0.94 & 1.47 & 0.73 \\
1998 & 0.31 & 0.30 & 0.43 & 0.78 & 1.29 & 0.56 \\
1999 & 0.23 & 0.16 & 0.29 & 0.72 & 1.39 & 0.60 \\
2000 & 0.15 & 0.19 & 0.29 & 0.72 & 1.69 & 0.75 \\
2001 & 0.24 & 0.30 & 0.34 & 0.78 & 1.82 & 0.73 \\
2002 & 0.31 & 0.25 & 0.41 & 0.83 & 0.77 \\
2003 & 0.50 & 0.24 & 0.32 & 0.84 & 0.92 & 0.82 \\
\hline
\end{tabular}

(*) No statistical significance was detected for ratio deaths temporal changes, except for women aged 30-39 years. $(p<0.05)$.

ases and all types of stroke, no differences were obtained for stroke subtypes, except for "ill-defined stroke" signifying a substantial switch from "ill" to "well" defined stroke death cases.

The diffe rence of temporal changes for each st roke subtypes can be more detailed considering the evolution of mortality rates by age strata as shown at Table 3. For men, the declining risk of stroke death was observed for all ages; however, there was a discrepancy when the subtypes were analyzed separately. Intracerebral hemorrhage death rates had a significant decline for the 30-39 years-old and 60-69 years-old age strata; and cerebral infarction rates had a fall for the 40-49 yearsold and 70-79 years-old. Among women a different behavior was observed with a significant downtrend being detected only for women over 50 years-old for all types of stroke; and for women deceased due to intracerebral hemorrhage aged 30-39 years-old.

Table 4 displays the ratio between cerebral infarction and intracerebral hemorrhage during the time interval according to age-strata. Except for women aged 30 to 39 years-old, no significant changes were detected.

\section{DISCUSSION}

The description of age-adjusted mortality rates in the city of Sao Paulo showed an impressive decline during this time interval, mainly for men, in which the annual fall of stroke rates surpassed the decline observed for all cardiovascular diseases mortality rates. This trend was similar to that observed during the 1970/80 years in the city and the state of Sao Paulo ${ }^{1-3}$. The impact of death notification imp rovement can be confirmed by the switch of the most frequent stroke category, from ill-defined st rcke (1996) to intracerebral hemorrhage (2003).

Among males, there was an indisputable decline for both intracerebral hemorrhage and cerebral infarction deaths during this time. However, for females, the mortality rate trends for intracerebral hemorrhage and cerebral infarction was a ffected by the improvement of clinical diagnosis secondary to the increment of radiographic exams. The remarkable decreasing proportion of cases classified as "ill-defined stroke" favors the speculation that the "no-change" trend observed among women was probably false, due to the migration from "ill defined stroke" to other stroke subcategories. It is also possible to consider that every time a new classification is launched, even if not is changing for a specific disease, there is a lot of discussion of classification rules of diseases by physicians and nosologists.

The evolution of stroke mortality among other countries was described by the World Health O rganization around world from 1968 to 1994 for people aged 35 to 74 years-old (with no data from Brazil). There was a typical pattern from North America, Japan and Western Europe with a steep de- 
cline in all these places. However, among other countries as Romania, the Russian Federation, Latvia, Estonia there was an increase in stroke mortality rates ${ }^{8}$. Our data are showing that in São Paulo, Brazil, the trend of mortality rates was similar to the observed among other Westem countries except for Eastern Europe.

Compared to England and Wales (ratio of ischemic/hemomhagic stroke for both gender 35-74 years-old of 0.38 in 1999), our study showed a higher ratio during this time interval. As pointed $p$ re viously ${ }^{6}$, mortality studies did not represent the only source of data to verify the distribution of stro ke subtypes. In the city of Sao Paulo, there are two studies with different populations and designs that verified the ratio of ischemic/hemorrhagic stroke. An accurate post-hoc analysis of hospitalization from the emergency ward due to stroke disclosed an ischemic/hemorhagic ratio of 2.1 in a community hospital during the $1990 \mathrm{~s}^{9}$ Other study, an autopsy-based analysis of sudden death also in the city of Sao Paulo ${ }^{10}$ revealed that the ischemic/hemorrhagic ratio was close to 0.40 . Very similar the ratio obs e red for autopsy series in England during the $1940 s^{7}$. The discrepancy among mortality data, hospitalization, and autopsy series is not new finding. As stated by Sarti in 2000, "trends in mortality from stroke do not necessary reflect stroke occurrence in many countries. We know that trends in stroke incidence do not always parallel the trends in mortality from stroke. Although declining trends have been observed in mortality, trends in incidence can be flat or even increase" 10 .

Mortality studies using death certifications are an inexpensive, easy and standardized method to chronic disease assessment, but specifically for cereb rovascular diseases there were some problems in past observation studies as the WHO-MONICA ${ }^{11}$. Thus, it will be interesting to fund new studies in sentinel hospitals or using communities collecting data from stroke hospitalization and incidence, as p roposed by the World HealthOrganization ${ }^{12}$. In this perspective, other methods as the "Trial of Org 10172 in Acute Stroke Treatment" (TOAST) ${ }^{13}$ and the Oxford s h i reCommunity Stroke Pro je ct ${ }^{14}$ that combine clinical, radiographic and angiographic data will be more useful than only mortality data.
It will be useful to comprehend how important is the burden of risk factors, as high blood pressu$\mathrm{re}$, and both incidence and case-fatality rates due to different stroke subtypes. Other important issue is to consider a different social evolution pattern in diffe rent stroke subtypes. Particularly, in the city of Sao Paulo, it was detected that stroke have a higher risk of death chance among people living in deprived neighborhoods ${ }^{15}$.

Concluding, there was a significant decline in st roke mortality mainly due to "ill-defined stroke" for both gender. Only for men it was possible to detect a decline of both cerebral infarction and hemorrhagic stroke deaths.

\section{REFERENCES}

1. Lolio CA, Souza JMP, Laurenti R. Decline in cardiovascular disease mortality in the city of S. Paulo, Brazil, 1970 to 1983. Rev Saúde Pública 1986;20:454-464.

2. Lolio CA, Laurenti R. Trends in mortality due to cerebrovascular diseases in adults over 20 in the municipality of Sao Paulo (Brazil), 1950 to 1981. Rev Saúde Pública 1986;20:343-346.

3. Lotufo PA, Lolio CA. Trends of mortality from cerebrovascular disease in the State of São Paulo: 1970 to 1989 Arq Neuropsiquiatr. 1993;51:441-446.

4. Mansur AP, Souza MFM, Favarato D, et al. Stroke and ischemic heart disease mortality trends in Brazil from 1979 to 1996. Neuroepidemiology 2003;22:179-183.

5. Ministério da Saúde (BR). Saúde Brasil 2004: uma análise da situação de saúde. Brasilia (DF); 2004. cap. 5, : Temas especiais: uma análise de séries temporais de causas de morte selecionadas.

6. Lotufo PA, Bensenor IM. Stroke mortality in São Paulo (1997-2003): a description using the Tenth Revision of the International Classification of Diseases. Arq Neuropsiquiatr 2004;62:1008-1011.

7. Lawlor DA, Smith GD, Leon DA, Sterne JA, Ebrahim S. Secular trends in mortality by stroke subtype in the 20th century: a retrospective analysis. Lancet 2002;360:1818-1823.

8. Radanovic M. Characteristics of care to patients with stroke in a secondary hospital. Arq Neuropsiquiatr 2000;58:99-106.

9. Aikawa VN, Bambirra AP, Seoane LA, Bensenor IM, Lotufo PA. Higher burden of hemorrhagic stroke among women: an autopsy-based study in São Paulo, Brazil. Neuroepidemiology. 2005;24:309-316.

10. Sarti C, Rastenyte D, Cepaitis Z, Tuomilehto J. International trends in mortality from stroke, 1968 to 1994 . Stroke 2000;31:1588-1601.

11. Asplund K, Bonita R, Kuulasmaa K, et al. Multinational comparisons of stroke epidemiology: evaluation of case ascertainment in the WHO MONICA Stroke Study. Stroke 1995;26:355-360.

12. Truelsen T, Bonita R. Surveillance of stroke: the WHO stepwise approach. Summary. Geneva: World Health Organization, 2002.

13. Adams HP Jr, Bendixen BH, Kappelle LJ, et al. Classification of subtype of acute ischemic stroke: definitions for use in a multicenter clinical trial. TOAST. Trial of Org 10172 in Acute Stroke Treatment. Stroke 1993;24:35-41.

14. Lindley RI, Warlow CP, Wardlaw JM, Dennis MS, Slattery J, Sandercock PA. Interobserver reliability of a clinical classification of acute cerebral infarction. Stroke 1993;24:1801-1804.

15. Lotufo PA, Bensenor IM. Social exclusion and stroke mortality: P 349 Stroke 2005;36:505. 